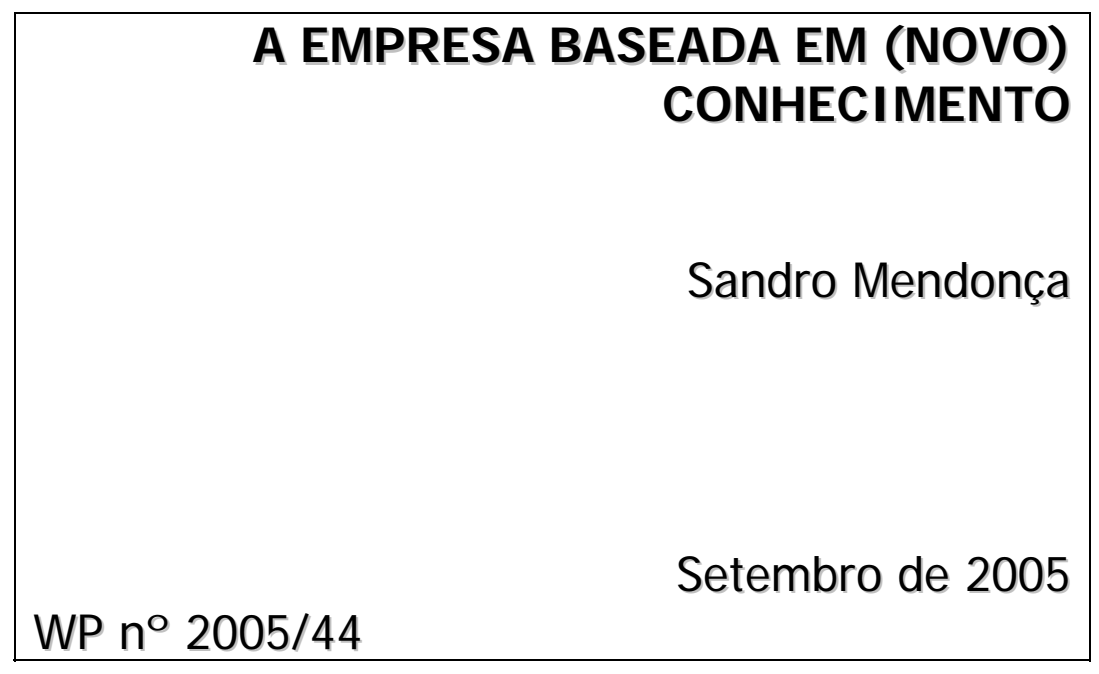

DOCUMENTO DE TRABALHO

WORKI NG PAPER 


\section{A EMPRESA BASEADA EM (NOVO) CONHECIMENTO}

Sandro Mendonça

(sfm@iscte.pt)

WP no 2005/44

Setembro de 2005

\section{INDICE}

RESUMO

1. INTRODUÇÃO

2. A INOVAÇÃO E A EMPRESA

2.1 Tecnologia $\quad 4$

2.2 Organização $\quad 9$

3. UMA EMPRESA EXPERIMENTAL 12

3.1 Economia no Laboratório $\quad 12$

3.2 Descrição da Experiência 13

3.3 Da Empresa Optimizadora à Empresa Inovadora 15

4. O CONHECIMENTO E A APRENDIZAGEM NAS EMPRESAS 19

4.1 Recursos, Rotinas e Competências $\quad 21$

4.2 Características das Empresas Inovadoras $\quad 23$

4.3 Tendências Recentes na Organização da Inovação 25

5. CONCLUSÕES

$\begin{array}{ll}\text { BIBLIOGRAFIA } & 29\end{array}$ 


\section{A EMPRESA BASEADA EM (NOVO) CONHECIMENTO ${ }^{1}$}

\section{$\underline{\text { Resumo }}$}

Uma empresa pode ser entendida como uma organização que resolve problemas com valor económico para os clientes. Nesta perspectiva, a compreensão dos mecanismos de produção e reprodução de conhecimento economicamente útil surge como essencial para a análise do processo contínuo que é a actividade económica, cujo protagonista central nas sociedades capitalistas continua ser a empresa. O texto discute a relação entre tecnologia e organização, com base num caso ilustrativo de economia experimental e com base na literatura teórica e empírica sobre o fenómeno da inovação.

Palavras-Chave: inovação, rotinas, competências dinâmicas

Título Cabecalho: A empresa inovadora

\section{Documento De Trabalho}

A publicar em Jorge F. Gomes, Miguel Pina e Cunha e Arménio Rego (Coord.), Comportamento Organizacional e Gestão: 21 Temas e Debates para o Século XXI, Lisboa: RH Editores.

\footnotetext{
${ }^{1}$ Sandro Mendonça, Dinâmia e Departamento de Economia, ISCTE e SPRU, The Freeman Centre, University of Sussex, Brighton, East Sussex, BN1 9QE, UK.
} 


\section{INTRODUÇÃO ${ }^{2}$}

O presente texto tem como objectivo geral apresentar uma interpretação abrangente e integrada do fenómeno das empresas inovadoras. Mais precisamente, pretende-se contribuir para uma melhor compreensão da emergência, funcionamento, evolução e importância das organizações empresariais que assentam as suas vantagens competitivas no desenvolvimento contínuo de competências técnicas numa economia global crescentemente baseada no conhecimento. Estas empresas são agentes socioeconómicos complexos sendo que o modo multidimensional como operam e se relacionam com a envolvente torna a sua investigação uma tarefa difícil mas necessariamente multidisciplinar e fascinante. Trata-se também de uma agenda de investigação da qual cidadãos, gestores e decisores públicos esperam cada vez mais tirar conclusões práticas. Valerá a pena continuar a investir neste objecto de trabalho no futuro, uma vez que o próprio objecto de estudo está em constante mutação.

Na nossa análise definiremos uma empresa como uma organização de pessoas e recursos tangíveis e intangíveis que se dedica a resolver problemas com valor económico para os clientes. No fundo todas as organizações são fundadas em conhecimento, conhecimento de como produzir e como organizar a sua vida económica. Não existem, em princípio, empresas baseadas na ignorância. Estamos, portanto, preocupados em compreender a empresa que gera e utiliza novo conhecimento. Nesta perspectiva, a compreensão dos mecanismos de produção e reprodução de competências surge como essencial para a análise do processo contínuo que é a actividade económica, cujo protagonista central nas sociedades capitalistas é a empresa. Este ensaio propõe-se, então, identificar, discutir e propor interpretações próprias de um conjunto de categorias básicas que têm dominado o debate de teóricos das organizações e investigadores do fenómeno da inovação, literatura onde se tem apontado o conhecimento economicamente útil como um recurso crítico à sustentação de vantagens competitivas ao longo do tempo.

A segunda secção começa por pôr em evidência a própria pertinência da inovação tecnológica e organizacional para o crescimento económico e para a mudança socio-económica. A terceira secção utiliza um exercício de economia experimental para ilustrar o modo como surge a aprendizagem no contexto de uma empresa, a principal organização que materializa novo conhecimento em novos produtos e processos e os faz chegar aos mercados de utilizadores com maior ou menor sucesso. A quarta secção procura estabilizar os conceitos essenciais de economia e gestão da inovação assim como discutir implicações para a gestão e

\footnotetext{
${ }^{2} \mathrm{O}$ autor beneficiou da oportunidade de expor um primeiro esboço das ideias contidas neste artigo num seminário organizado a convite da Universidade de Évora. O autor agradece à audiência presente, em particular a Adão Carvalho e a Manuel Branco, pelo debate que se gerou. Os comentários de Ana Silva, Celso Rimoli, Luís Francisco Carvalho e Miguel Pinto revelaram-se preciosos para as sucessivas melhorias por que passou o texto. Quaisquer erros ou omissões são da exclusiva responsabilidade do autor.
} 


\section{A Empresa Baseada em (Novo) Conhecimento}

desenho da estrutura administrativa das empresas inovadoras. A quinta secção conclui com algumas observações finais.

\section{A INOVAÇÃO E A EMPRESA}

\section{Tecnologia}

Os estudos da inovação são um ramo jovem e em grande crescimento nas ciências sociais (ver figura 1). Ao mesmo tempo são uma área em que a análise teórica e empírica tem enformado abundantemente a condução dos assuntos práticos da vida económica, sobretudo no domínio da política pública. A experimentação de novos artefactos é um fenómeno tão antigo como a própria humanidade, não falta por isso objecto de estudo a quem procure investigar a inovação. $\mathrm{O}$ ambiente à nossa volta é humanizado. Os utensílios de que hoje nos servimos, por exemplo cadeiras, mesas, relógios, agrafadores, computadores, e cuja origem muitas vezes não questionamos, não existiam na natureza. Alguns dos momentos mais marcantes da história estão relacionados com a utilização dos primeiros utensílios feitos de pedra há cerca de dois milhões de anos, o desenvolvimento das técnicas agrícolas há 13.000 anos ou a invenção da escrita por volta de 3.000 A.C. (Diamond, 1998). A revolução industrial da segunda metade do século XVIII marcou uma aceleração sem precedentes da mudança tecnológica.

Figura 1. A problemática da inovação - uma área de estudo em crescimento

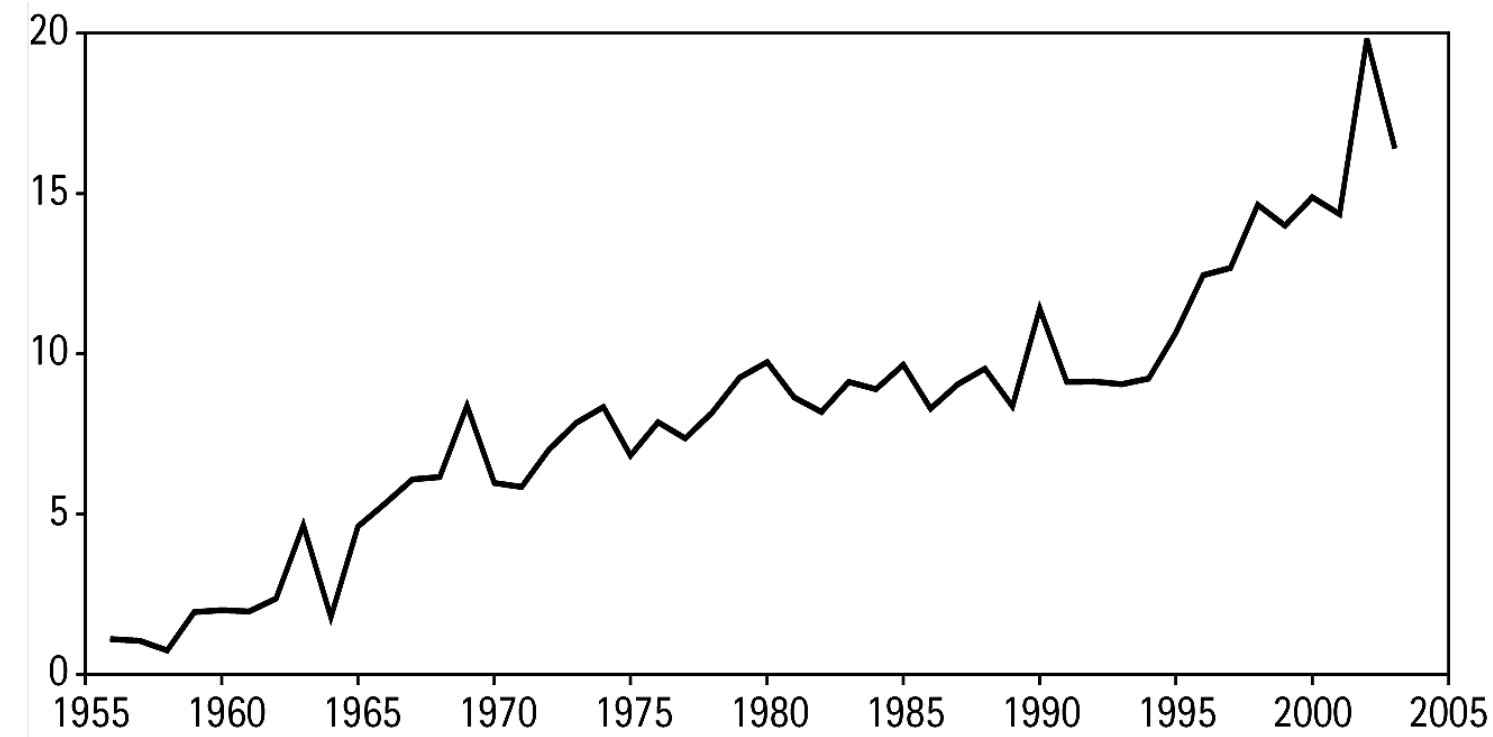

Nota: Artigos com a palavra "inovação” no título por cada 10.000 artigos nas ciências sociais.

Fonte: Fagerberg (2004), sobre dados originais ISI Web of Knowledge.

Estes objectos que nos rodeiam foram sendo sucessivamente criados ao longo da história e são fruto de um processo colectivo e contingente, dependente de interacções complexas e evolutivas entre várias personagens (inventores, empresas, universidades, agências reguladoras, laboratórios públicos, consumidores, etc.). As 


\section{A Empresa Baseada em (Novo) Conhecimento}

inovações representam um acumular de novas ideias e uma expansão do portfolio de saber dos actores sociais. De modo mais subtil, as inovações revelam também a capacidade de gerar novo conhecimento. Nas sociedades contemporâneas, a mudança tecnológica e organizacional não dá sinais de abrandar, motivando perplexidades e ansiedades, testando mentalidades e contaminando a retórica quotidiana de agentes públicos e privados. A inovação é ela própria um objecto de investigação em mutação, criando cada vez mais necessidade de novas explicações. Compreender melhor o fenómeno da inovação, as suas causas e consequências é também uma condição básica para os gestores e os fazedores de política pública aprenderem a intervir e a adaptar-se melhor a um mundo em mudança.

A introdução da noção de inovação nas ciências sociais, e em particular nas ciências económicas e empresariais, deve-se sobretudo a Joseph Schumpeter (ver caixa 1 ). ${ }^{3}$ A preocupação com este tema veio depois a tornar-se um campo interdisciplinar que estuda os relacionamentos entre mudanças económicas, tecnológicas, organizacionais e institucionais. Na sua obra publicada em inglês em 1934, mas originalmente publicada em alemão em 1911, Theory of Economic Development, Schumpeter argumenta que são os empresários/empreendedores (entrepreneurs) que injectam novidade no sistema económico e que é esta actividade que explica a instabilidade inerente ao desenrolar da actividade económica; a sua qualidade particular é saber reunir. desenvolvimento económico consiste, então, num processo de mudança qualitativa cujas causas não são exógenas mas, pelo contrário, são intrínsecas à própria vida económica. Para Schumpeter, tal como antes para Marx, a competição inter-empresarial essencialmente tecnológica.

Caixa 1. Joseph Alois Schumpeter (1883-1950)

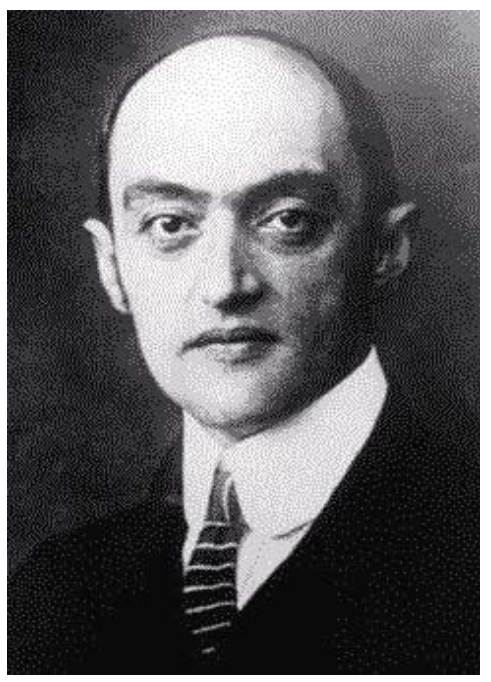

Schumpeter doutorou-se em economia em Viena. Para além de professor, o papel que mais define a sua vida, foi também a intervalos advogado e ministro das finanças. Em 1934 muda-se para a Universidade de Harvard. Embora se visse originalmente como um seguidor da escola do equilíbrio geral de Walras, o seu trabalho acaba por representar uma ruptura radical com os pressupostos centrais da economia neoclássica. Para Schumpeter, a característica essencial do capitalismo é a tendência permanente para o desequilíbrio. Para o estudo da economia Schumpeter advogava uma abordagem que designava por reasoned history, isto é, análise histórica conceptualmente clarificada.

\section{A realidade capitalista é}

definida não tanto pela competição baseada nos preços, mas antes pela introdução incansável de novos produtos, de ovas tecnologias, de novas fontes de matérias-primas, de novos tipos de organização e pela abertura de novos mercados. Nesta visão, é aos empresários que compete a função social específica de introduzir no mercado novas combinações ou re-arranjos de ideias, equipamentos e outros recursos

\footnotetext{
${ }^{3}$ Para discussões recentes do significado da obra de Schumpeter ver Fagerberg (2003) e Freeman e Louçã (2001).
} 


\section{A Empresa Baseada em (Novo) Conhecimento}

existentes. A Schumpeter devemos, também, a distinção clássica entre invenção e inovação: a invenção corresponde à descoberta de uma nova ideia (criação de novo conhecimento), enquanto a inovação corresponde à primeira tentativa de comercialização no mercado dessa ideia sob a forma de um novo produto ou processo (transformação de conhecimento em artefactos ou serviços economicamente úteis).

Nos seus trabalhos mais tardios, como no livro Business Cycles de 1939, Schumpeter torna mais explícita a ligação entre inovação e crescimento económico, ao fazer notar que as inovações tendem a concentrar-se em certos períodos em determinados sectores que tendem a crescer a um ritmo acima da média da economia. Após a introdução de uma inovação (radical) surge uma multidão de imitadores que tentam beneficiar do sucesso e, por vezes, a propor versões alteradas (inovações incrementais), o que contribui para expandir a indústria em questão. A recompensa económica da inovação é por isso transitória. O próprio crescimento eventualmente desvanecer-se-á, dando lugar a movimentos cíclicos ao nível macroeconómico. Este padrão de interacção entre inovação e imitação é também um modo de conceber o processo de difusão das inovações. A conjunção destes factores seria uma hipótese explicativa das ondas longas que afectam o percurso dos sistemas económicos capitalistas. Schumpeter admite também que a actividade empreendedora pode ser organizada colectivamente. Na primeira fase do seu pensamento, o empreendedor individual aparecia quase como uma figura heróica predestinada a destruir o equilíbrio, alguém excepcional que se desvia das normas sociais. Na fase conhecida como "Schumpeter tipo II", o destaque é dado à emergência das grandes empresas, onde a produção de invenções é realizada de modo continuado em laboratórios internos especializados. O processo de destruição criadora posto em marcha pela inovação era visto, assim, como fruto de uma actividade crescentemente mecanizada e burocratizada. A grande empresa substitui-se ao indivíduo como principal veículo da mudança tecnológica na economia. Esta é fase conhecida como “Schumpeter tipo II”, tal como expressa no célebre livro Capitalism, Socialism and Democracy de 1943. A evolução tecnológica deveria continuar a comandar os destinos do capitalismo, mas de maneira mais suave e com menos rupturas.

A partir da inspiração fornecida por Schumpeter, e devido à descoberta por Abramovitz (1956) e Solow (1957) de que a maior parte do crescimento económico não era explicada pela acumulação dos factores produtivos clássicos, trabalho e capital, vários investigadores passaram a dedicar-se ao estudo de aspectos relacionados com a referida mudança tecnológica. ${ }^{4}$ No entanto, o ressurgir das teorias de Schumpeter teve somente lugar no início da década de 1980 com os estudos empíricos de Freeman (1982) e com a proposta de uma teoria económica evolucionista por Nelson e Winter (1982) (ver caixa 2).

Caixa 2. Pensamento neoschumpeteriano e evolucionista

${ }^{4}$ Para o le 


\section{A Empresa Baseada em (Novo) Conhecimento}

Chris Freeman (sozinho na foto) é um dos fundadores do SPRU - Science Policy Research Unit, da Universidade de Sussex no Reino Unido. Pioneiro de uma abordagem multidisciplinar da inovação, o SPRU tornou-se a instituição que mais influenciou a investigação nesta área, sobretudo na Europa, Ásia e América Latina.

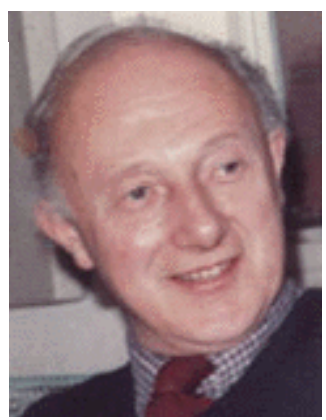

Richard Nelson e Sidney Winter foram autores de um das mais importantes obras sobre a dimensão económica da inovação, An Evolutionary Theory of Economic Change (1982). Estes dois economistas norte-americanos, que se conheceram na famosa Rand Corporation, advogam a prática de teorização apreciativa para a compreensão do fenómeno da mudança qualitativa técnica e institucional, ou seja, uma metodologia baseada na identificação de

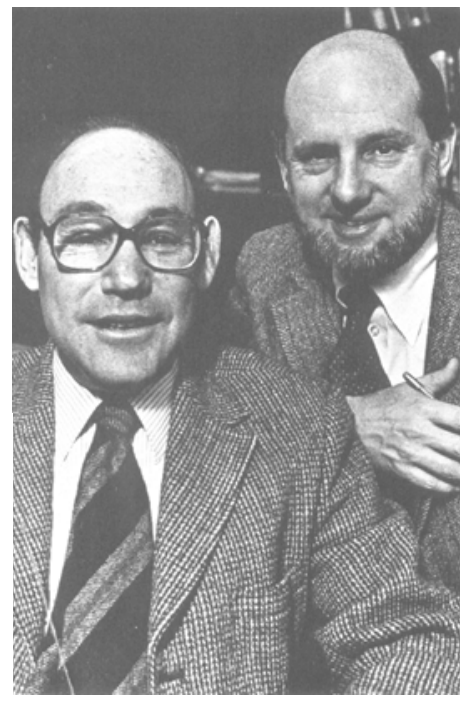
factos estilizados com vista ao esboço de generalizações.

A linha de investigação herdeira de Schumpeter tem sido responsável por uma canalização de atenção para o fenómeno da mudança socioeconómica, colocando a inovação e o conhecimento no centro da análise. ${ }^{5}$ É em grande parte nesta literatura que se baseia o presente texto (ver caixa 3). Nesta literatura a tecnologia é definida como uma colecção de conhecimentos articulados sobre o mundo físico, os quais são traduzidos em produtos ou processos de produção. Deste modo, o conceito de tecnologia não deve ser confundido com os artefactos que a materializam, embora em muitos casos tecnologia e artefactos sejam utilizados como sinónimos. A tecnologia é igualmente muito mais que informação codificada em manuais de instruções ou livros técnicos. É saber como resolver problemas complexos de pesquisa, desenho, desenvolvimento, teste e fabrico de produtos que funcionam e são úteis (Pavitt, 1998).

O modo como a tecnologia evolui pode ser entendido como uma sucessão de rupturas e períodos de desenvolvimento perdurável, tal como Thomas Kuhn defendia no caso da ciência. Dosi (1982) descreve o processo de inovação com base em três elementos básicos. Um paradigma tecnológico é entendido como um mapa cognitivo dos problemas, das crenças e das soluções derivadas de um conjunto de relações técnicas e princípios de engenharia. Um paradigma define as prioridades e os métodos aceitáveis para a obtenção de novo conhecimento, assim como as expectativas dos actores. No campo de possibilidades aberto pelo paradigma, os esforços de investigação desenvolvem-se ao longo de determinadas trajectórias tecnológicas. Uma dada trajectória diz respeito ao processo de desdobramento de novas tecnologias dentro das possibilidades delimitadas pelo paradigma. Uma trajectória cria a expectativa que haja uma sequência de inovações, certamente diferentes, mas relacionadas, que vão contribuindo para a acumulação de saber numa

\footnotetext{
${ }^{5}$ As obras de síntese mais marcantes na área dos estudos de inovação são Dosi et al. (1988) e Fagerberg et al. (2004). Para um survey recente sobre as principais promessas, avanços e insuficiências das várias agendas de investigação sobre inovação ver Castellacci et al. (2005).
} 


\section{A Empresa Baseada em (Novo) Conhecimento}

determinada área da técnica. Uma inovação é muitas vezes o fruto de um processo e não um evento isoladō. Por fim, como heurística entende-se um certo tipo de abordagem que se convenciona empregar como resposta aos desafios técnicos que vão surgindo. Uma heurística é uma "regra de bolso" que ajuda os agentes da inovação a progredirem ao longo de uma certa trajectória tecnológica.

Caixa 3. Obras de referência em economia e gestão da inovação

A década de 1980 assinala uma consolidação das reflexões sobre a mudança técnica e institucional. Um conjunto de obras de referência, indicadas abaixo, constituíram marcos na teorização do fenómeno da inovação e na transmissão das lições aprendidas para gestores e responsáveis por políticas de ciência e tecnologia:

Dosi, Freeman, Nelson, Silverberg \& Soete (1988), Technical Change and Economic Theory

Fagerberg, Mowery \& Nelson (2004), The Oxford Handbook of Innovation

Freeman \& Louçã (2001), As Time Goes By

Freeman \& Soete (1997), The Economics of Industrial Innovation

Landes (1969), The Unbound Prometheus

Lundvall (1992), National Systems of Innovation

Nelson \& Winter (1982), Evolutionary Theory of Economic Change

Rosenberg (1982), Inside the Black Box

Rosenberg (1994), Exploring the Black Box

Tidd, Bessant \& Pavitt (2001), Managing Innovation

von Tunzelmann (1995), Technology and Industrial Progress

A literatura empírica sobre inovação contribuiu também para desalojar o modelo linear da inovação que definia, e ainda influencia, a visão convencional da mudança técnica. A premissa desta visão é que o processo de inovação passa primeiro por descobrir princípios científicos gerais, para seguidamente se desenvolver uma tecnologia concreta que depois é transferível para quem vai conceber novos artefactos comercializáveis no mercado. A inovação é vista como ciência aplicada. O corolário é que bastaria o investimento em investigação, a montante, para gerar novos produtos e processos, a juzante. Kline e Rosenberg (1986) problematizaram esta direcção causal com dois contra-argumentos. Em primeiro lugar, embora algumas inovações importantes tenham dependido de descobertas científicas, esta não é verdadeira na maioria das vezes. Grande parte do novo conhecimento industrialmente aplicável no dia a dia das empresas, e muitas inovações, são criadas por ajustamentos marginais de tecnologias existentes. Em segundo lugar, o modelo linear ignora que se verificam muitas interacções entre as diferentes etapas, e que estes efeitos de acção-retroacção podem ser convergentes ou divergentes, portanto imprevisíveis, podendo eventualmente conduzir a soluções totalmente novas. A natureza aberta e interactiva da inovação permite compreendê-la de uma forma sistémica. As inovações e as empresas tomadas isoladamente não são suficientes para explicar a mudança socioeconómica. Devem por isso ser entendidas como elementos de sistemas maiores, nos quais vários actores interdependentes co-evoluem com a mudança tecnológica. A visão sistémica desenvolveu-se a partir de meados da década de 1980, com os trabalhos de Freeman (1987) e 


\section{A Empresa Baseada em (Novo) Conhecimento}

Lundvall (1992). Esta abordagem sustenta que a inovação resulta de um processo de interacção continuada entre diferentes indivíduos, organizações, instituições e redes de actores ao nível regional (Asheim e Gertler, 2004), sectorial (Malerba, 2004), nacional (Edquist, 2004) e transnacional (Freeman, 2002).

\section{Organização}

O presente contributo ocupa-se dos aspectos dinâmicos da articulação entre tecnologia e organização. O conceito de organização pode ser equacionado a partir das formas organizacionais propriamente ditas (como certos tipos de empresas) ou, de um modo mais geral, a organização pode ser também entendida como um conjunto de conhecimentos sobre o modo de governar um conjunto de pessoas e recursos tangíveis ou intangíveis para atingir certos fins. Esta noção de organização leva a questionar a origem e os percursos evolutivos da instituição do capitalismo que mais nos interessa analisar para efeitos deste capítulo, a empresa moderna, mas também a inquirir a importância das empresas para a geração de novo conhecimento economicamente útil.

A evidência empírica diz-nos que a importância das empresas para a inovação cresceu ao longo do século XX. O quadro 1 apresenta dados de patentes para ilustrar a tendência para as empresas surgirem como o principal locus de construção de competências tecnológicas, enquanto o sector público se especializou no desenvolvimento da ciência básica. As fontes de patentes de invenção mudaram ao longo do último século, não só nos EUA como na Europa, e tornaram-se inclusivamente um indicador da capacidade de uma economia gerar inovação de um modo sustentado. Por exemplo, em 1998 cerca de 65\% das patentes em Portugal eram pedidas por inventores independentes, em contraste com cerca de 35\% na Finlândia e na Suécia, sendo que este facto pode ser mobilizado para descrever a imaturidade do sistema de inovação português (Mendonça et al., 2004). Ao longo do século XX, a importância das empresas no desenvolvimento de actividades tecnológicas tornou-se ainda mais pronunciada, comparando com o seu peso produção e no emprego por exemplo. Hoje em dia, o peso das empresas na investigação e desenvolvimento (I\&D) está entre 50\% e 80\% nas economias mais avançadas; Portugal tem neste aspecto novamente um padrão contrário (Godinho et. al., 2003). Dentro da I\&D privada as grandes empresas (> 10000 trabalhadores) têm um grande peso (cerca de $80 \%$ do total). Ao nível das grandes empresas a concentração da actividade de I\&D é ainda mais elevada do que a concentração das quotas de mercado e de emprego (Patel e Pavitt, 1995).

Quadro 1. Patentes atribuídas nos EUA, valores aproximados

\begin{tabular}{ccc}
\hline Ano & Empresas & Indivíduos e outros \\
\hline 1900 & $20 \%$ & $80 \%$ \\
1980 & $80 \%$ & $20 \%$ \\
\hline
\end{tabular}




\section{A Empresa Baseada em (Novo) Conhecimento}

Fonte: Patel e Pavitt, 1995.

O papel das empresas na geração de novas ideias não deve surpreender, dado que estas são o actor principal do sistema económico dito de mercado, o modo dominante de coordenação da actividade económica, caracterizado pela liberdade de iniciativa individual e pela existência de direitos de propriedade privada. As empresas são as organizações que explicam a maior parte da produção, emprego e riqueza criada nas economias contemporâneas. Não surpreende também que a origem e evolução deste tipo de actor económico estejam marcadas por três momentos estruturantes do processo de desenvolvimento histórico do sistema capitalista desde os finais do século XVIII até ao século XX.

A Primeira Revolução Industrial (1750-1815) ${ }^{6}$, que surge no Reino Unido ligada às novas tecnologias de então, sobretudo o motor a vapor e infra-estruturas como os canais, representa também uma era de transição do artesanato para a produção industrial colectivamente organizada. Menos reconhecido é este último aspecto, o facto de que o sistema fabril pode ser descrito como a principal inovação organizacional desta época (Freeman e Louçã, 2001; Mokyr, 2002). Até aí os artesãos trabalhavam ao seu ritmo; vão passar a estar sujeitos à rígida disciplina imposta pelos supervisores e pelo relógio. Os trabalhadores são cada vez mais afectos a tarefas específicas e simples e deixam de estar presentes em todas as fases do processo produtivo, deixando também de dominar todos os aspectos técnicos que permitem transformar inputs em outputs. A relação laboral contratualiza-se, passando de um contexto semifamiliar para uma relação formal entre trabalhador e empregador, registando-se concomitantemente uma crescente separação física entre o local de produção (fábrica) e o local de consumo (domicílio). Registam-se também muitas mudanças sociais complementares, nomeadamente os movimentos de urbanização e proletarização (Landes, 1969). A estrutura industrial desta época caracterizou-se por uma pulverização em muitas pequenas empresas não empregando mais de 100 trabalhadores, pelo que os mercados eram fluidos e podiam ser descritos sem dificuldade como funcionando por meio de uma "mão invisível”. Ainda assim, as mudanças na organização produtiva estimularam a invenção de máquinas para substituir o trabalho manual no desempenho de um número crescente de operações.

Adam Smith, atento observador dos problemas do seu tempo, inicia a sua famosa obra A Riqueza das Nações notando precisamente todas estas transformações. Como na sua célebre discussão sobre os ganhos de divisão do trabalho numa fábrica de alfinetes do trabalho, no primeiro capítulo do primeiro volume do seu livro. Ao contrário do que se viria a constituir como ciência económica dominante no século XX, Smith funda o seu trabalho numa análise empírica de processos dinâmicos, dando especial atenção ao problema da coordenação. Schumpeter, na sua faceta de historiador do pensamento económico, chegou mesmo a

\footnotetext{
${ }^{6}$ Para a delimitação das revoluções industriais baseamo-nos em von Tunzelmann (2003).
} 


\section{A Empresa Baseada em (Novo) Conhecimento}

considerar que, para Smith, a divisão do trabalho era a causa primordial do crescimento económico (Ekelund e Hérbert, 1990, p. 119).

A empresa moderna é um fenómeno novo na história do capitalismo. Especificamente, é o principal fenómeno organizacional que emerge com a Segunda Revolução Industrial (1870-1914). Este período é marcado por uma constelação de tecnologias radicalmente novas, a electricidade, a química sintética e o motor de explosão, e um conjunto de novas infra-estruturas de transporte e comunicação, i.e. o caminho-deferro, o navio a vapor e o telégrafo. Esta época caracteriza-se pelo desenvolvimento de empresas grandes e gigantes, muitas delas ainda hoje existentes como, por exemplo, a Bayer, a BASF, a Siemens, a Shell, a Ford, a GE, a Du Pont, etc. São estas empresas, grandes hierarquias constituídas como "sociedades anónimas”, que corporizam o novo sistema de governação de operações a que chamamos aqui empresa moderna. De acordo com a visão de Chandler (1990), os traços essenciais são a separação entre propriedade e controlo, o aparecimento de uma classe de gestores profissionalizados e a produção em massa. A empresa moderna, como forma dominante de abordagem aos problemas ligados à coordenação de actividades complexas, contínuas e em grande escala, representa a transição para um modo de governação por meio de “mão visível”. Paralelamente, a necessidade de mobilizar o investimento necessário às novas indústrias intensivas em capital leva ao desenvolvimento dos mercados financeiros e das bolsas de valores, como instituições básicas de suporte à condução da actividade económica.

É também nesta época que é fundado o primeiro laboratório empresarial pela empresa química Bayer (no ano de 1881). A institucionalização de unidades de I\&D no seio da grande empresa mudou radicalmente o modo como as empresas competem e actuam sobre as tecnologias que dominam (Freeman, 1982). É esta inovação organizacional que Schumpeter constata e considera uma mutação irreversível no processo de criação de inovações.

Os dias de hoje são marcados por outra grande ruptura, tanto nas tecnologias que estão na base das necessidades e desejos das pessoas, como nas formas como as organizações conduzem as suas actividades e negócios. É consensual entre muitos observadores contemporâneos que vivemos em plena Terceira Revolução Industrial (1973- ). ${ }^{7}$ As inovações-chave desta revolução são as tecnologias de informação e comunicação (circuito integrado, Internet, etc.), a biotecnologia e os novos materiais. A inovação organizacional associada é a rede (Castells, 2000; Freeman e Louçã, 2001; Von Tunzelmann, 1995). As redes podem ser definidas como uma forma de governação da actividade socioeconómica entre o mercado anónimo (mão invisível) e a hierarquia integrada (mão visível). Neste cenário, as empresas surgem com um dos nós de um denso sistema de relações que envolve um leque diversificado de actores que também inclui

\footnotetext{
${ }^{7}$ Entre os autores que partilham esta visão encontram-se Freeman e Louçã (2001), Pavitt e Steimueller (2001), Pérez (2002), Arthur (2002), von Tunzelmann (2003).
} 


\section{A Empresa Baseada em (Novo) Conhecimento}

universidades, agências públicas, associações sectoriais, etc. A importância das redes significa que nenhum actor tem todo o saber ou os recursos necessários para enfrentar os problemas tecno-económicos mais relevantes para a prossecução dos seus objectivos. A história da Terceira Revolução Industrial é algo para a historiografia futura. É possível, no entanto, aprender lições válidas para o futuro através das experiências passadas e actuais.

\section{UMA EMPRESA EXPERIMENTAL}

\section{Economia no Laboratório}

A presente secção expõe e discute alguns resultados que advêm de um ensaio de economia experimental em que se procurou simular o funcionamento de uma unidade empresarial dotada de dois factores e empenhada na produção de um produto homogéneo. Esta experiência é usada como dispositivo pedagógico para ilustrar tópicos da teoria de empresa a alunos de economia e gestão do ISCTE. A experiência foi inicialmente concebida para replicar um objecto abstracto da teoria microeconómica empresa conhecido como "função de produção”, definido como as quantidades máxima de produção possível de obter com dadas combinações de factores. Contudo, com a repetição do exercício foi sendo possível constatar a ocorrência de "anomalias" que tornam este um caso interessante para explorar no contexto da economia neoschumpeteriana e da teoria das organizações, áreas de estudo não toldadas por premissas de "maximização" ou de "equilíbrio" típicas da microeconomia ortodoxa.

Em análise económica, os métodos de laboratório constituem uma ferramenta cada vez mais utilizada como forma de criar um ambiente propício para que as implicações de determinadas teorias sejam mais bem conhecidas. ${ }^{8}$ Durante muito tempo uma das premissas mais aceites entre os economistas era que não seria possível testar teorias por intermédio de experiências. Os principais obstáculos prendiam-se sobretudo com a natureza complexa e histórica dos objectos sociais e com a impossibilidade de reproduzir artificialmente o comportamento real de indivíduos, empresas, governos e mercados. As primeiras experiências explícitas de proposições teóricas económicas tiveram lugar nos EUA no final da década de 1940, princípios da de 1950. Hoje, entretanto, as experiências tornaram-se um recurso convencional da teoria económica. ${ }^{9}$ Os contributos que alimentam esta linha de investigação chegam actualmente de todos os domínios da ciência económica, incluindo economia pública, organização industrial, teoria dos jogos, etc. De acordo com Roth (1995, p. 22) os ensaios de laboratório são utilizados sobretudo para três fins essenciais: (i) testar predições teóricas em condições ideais, tal como na física ou na química (speaking to theorists); (ii) interpretar o significado e os

\footnotetext{
${ }^{8}$ Dois elementos de consulta essenciais nesta área são Davis e Holt (1992) e Hagel e Roth (1995).

${ }^{9}$ A legitimação final veio em 2002. Um prémio Nobel atribuído conjuntamente a Vernon Smith, um dos pioneiros da utilização de técnicas laboratoriais em economia, e a Daniel Kahneman, um psicólogo que, juntamente com Amos Tversky, estudou o papel das heurísticas no processo de decisão.
} 


\section{A Empresa Baseada em (Novo) Conhecimento}

efeitos de variáveis desvalorizadas pelas teorias existentes (searching for facts); (iii) e para desenhar mecanismos que permitam atingir determinado estado de coisas, tal como na engenharia (whispering in the ears of princes). A experiência que seguidamente se descreve tem como objectivo o segundo ponto.

\section{Descrição da Experiência}

Comecemos por descrever o cenário de partida. A nossa empresa comporta apenas um estabelecimento; é, portanto, uma fábrica. Existem dois recursos ou factores produtivos mobilizados para o processo produtivo: o capital e o trabalho. O capital é o factor fixo e consiste numa máquina (agrafador) e nas instalações (sala de aula, duas mesas juntas no meio da sala, um conjunto de cadeiras rodeando as duas mesas). O factor trabalho são os próprios alunos. O produto final a ser fabricado é um "livro". As matérias-primas a consumir por unidade de produto transformado são uma folha de papel A4 usado num dos lados e um agrafo. Para fazer um livro é necessário articular um conjunto de operações tais como tirar uma folha de uma pilha de papel, dobrar a folha, vincá-la, rasgá-la, dobrar novamente e agrafar num dos lados de modo a que se pareça com um bloco de papel que se pode desfolhar e "ler” os seus conteúdos. A fábrica opera em fracções de tempo de 60 segundos. O objectivo é produzir o maior número possível de livros com qualidade homogénea. Num primeiro momento de laboração a fábrica entrará em funcionamento com zero trabalhadores. Depois ir-se-á adicionando operários e medir-se-á o número de livros produzidos. À medida que aumenta a produção, regista-se a evolução da quantidade produzida e a produtividade do trabalho. A experiência pára quando as produtividades marginais decrescentes forem notórias na produção dos livros.

A representação gráfica gerada pela experiência ${ }^{10}$ é ilustrada pela figura 2. Para além de replicar, aliás notavelmente, a expressão gráfica da função de produção, o exercício permitiu focar a atenção dos alunos num conjunto de aspectos básicos da teoria do produtor. O exercício permite distinguir produção, produtividade média e produtividade marginal; permite clarificar a diferença entre factor variável e factor fixo (e, consequentemente, o significado do curto e do longo prazo em economia); finalmente, com a atribuição de preços aos factores, torna-se também possível observar a evolução do custo total, custo médio e custo marginal. No caso em questão, constata-se que o factor capital está a ser subutilizado quando o número de funcionários da fábrica é menor do que quatro e que uma empresa optimizadora nunca colocaria mais do que sete trabalhadores ao serviço, uma vez que poderia sempre produzir o mesmo com menos custos. Estes resultados são suficientes para tornar a experiência útil para alunos de nível introdutório; no entanto, emergem fenómenos cujas ressonâncias e significado já se encontram fora do âmbito da microeconomia convencional. Quais são? 


\section{A Empresa Baseada em (Novo) Conhecimento}

Figura 2. Função de produção

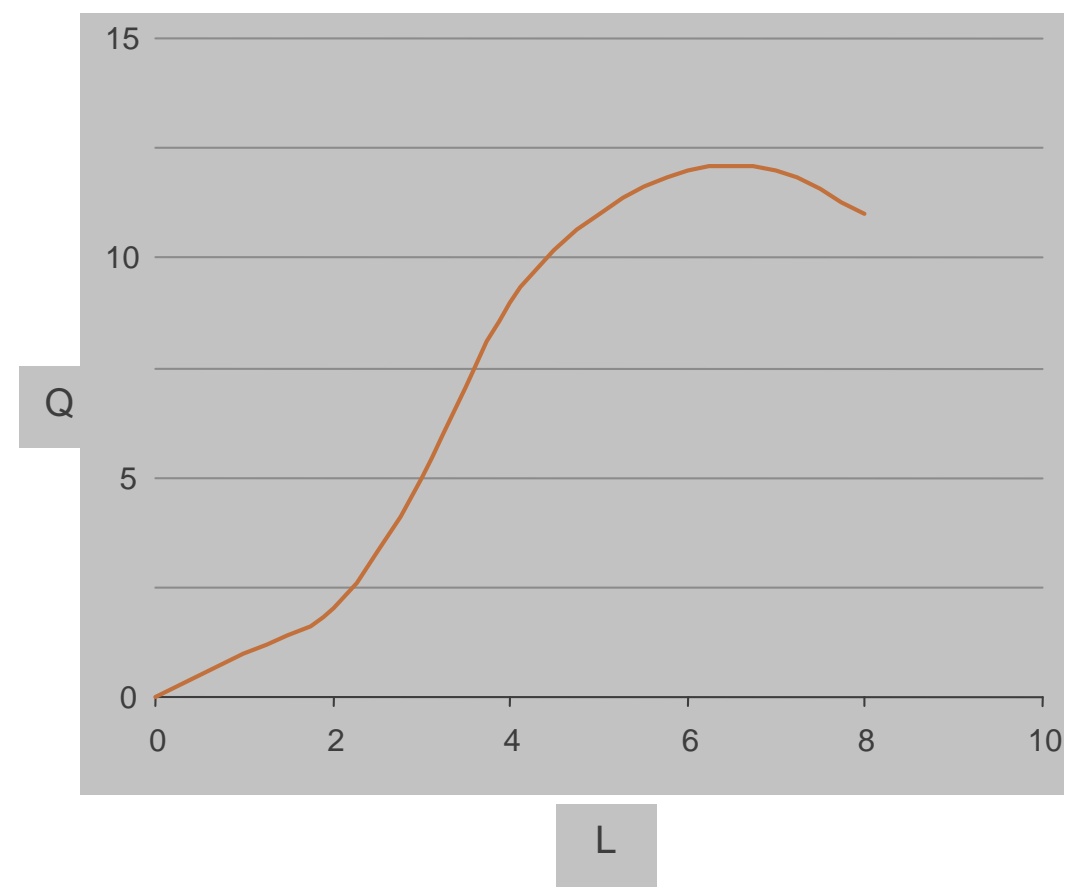

Fonte: Os dados são resultado da sessão realizada com os alunos da licenciatura em economia do ISCTE em 3 de Março de 2004.

\section{Da Empresa Optimizadora à Empresa Inovadora}

Organização. Em primeiro lugar, a organização do processo produtivo não é um aspecto residual. Os participantes da experiência chegam, mais cedo ou mais tarde, à conclusão de que faz sentido dividir tarefas e que essa estratégia é cada vez mais eficiente à medida que aumenta o número de funcionários da fábrica. Naturalmente, a divisão do trabalho torna-se cada vez mais fina à medida que aumenta o número de funcionários ao serviço e se produz mais. Alertar os participantes antes do início da experiência para os ganhos da divisão de trabalho é importante, de forma a evitar distorções nos dados que permitirão construir a função de produção. É curioso que, embora, Adam Smith (1776) inicie a Riqueza das Nações justamente pela descrição da organização fabril (o célebre exemplo da fábrica de alfinetes), os modernos manuais “standard” de microeconomia não contenham uma única referência à divisão do trabalho no seu índice remissivo. A simulação do funcionamento de uma fábrica, mesmo tendo sido concebida a partir de uma visão particular da ciência económica que é agnóstica em relação aos arranjos organizacionais específicos das empresas, prova que os mesmos são centrais para a compreensão do funcionamento das empresas (quase) reais.

\footnotetext{
${ }^{10}$ Resultados da sessão realizada com os alunos da licenciatura em economia do ISCTE em 3 de Março de 2004.
} 


\section{A Empresa Baseada em (Novo) Conhecimento}

Aprendizagem. Em segundo lugar, é possível observar mudanças qualitativas no desempenho das tarefas bem como na articulação das tarefas. A linha curva correspondente ao máximo de produção que é possível atingir com um determinado número de trabalhadores parece um pouco mais distorcida na vertical ("esticada para cima”) do que seria de esperar. Essa estranha distorção é uma elevação na vertical da curva que parece ocorrer sobretudo entre o terceiro e o quarto trabalhadores. Aos olhos dos promotores da experiência a origem desse fenómeno está associada à aprendizagem. De facto, o tempo em que a experiência decorre é o tempo histórico e os trabalhadores que já estão na fábrica nela permanecem quando chega mais um. Os participantes têm memória, acumulam informação da sua experiência prática e comunicam entre si durante e entre os períodos de laboração. Existe, portanto, aprendizagem e evolução dentro da fábrica. O novo conhecimento que é criado trata-se de um subproduto intangível da actividade normal de produção. Esta regularidade que se foi fazendo notar à medida que a experiência foi sendo repetida em diversas turmas está relacionada precisamente com outra ideia de Adam Smith, nomeadamente o facto de um trabalhador se tornar mais perito na função especializada que lhe compete.

Outros aspectos institucionais. A empresa experimental, embora sendo um exercício simples, pode ser utilizada para iluminar um conjunto de aspectos relevantes para a compreensão das empresas reais:

- O enquadramento da fábrica, como forma de juntar trabalhadores que se ocupam de um conjunto diferenciado de tarefas sob a mesma estrutura administrativa, é em si mesmo uma solução organizacional não discutida ou problematizada nos manuais introdutórios de economia;

- Outra questão que é evocada pela experiência tem que ver com a origem da fábrica: de onde aparece, quem toma iniciativa de juntar os factores de produção. Embora a economia convencional não tenha uma teoria específica sobre o empreendedorismo, é legítimo perguntar onde está o empresário schumpeteriano;

- Este exercício pedagógico também é revelador da complexidade organizacional das empresas reais. A divisão do trabalho permite observar directamente a emergência de uma estrutura funcional. Assim, é possível ver como as literaturas da economia e da gestão se encontram;

- A continuação da especialização poderá levar também a que surjam trabalhadores ocupados apenas em coordenar o trabalho dos outros e em garantir a fluidez do processo de fabrico. Esta observação permite evocar a teoria da agência. Uma vez que exista a necessidade de empregar gestores profissionais, os proprietários da empresa estão interessados em $i$ - escolher técnicos especializados para essa função (minimizando problemas de selecção adversa) e em ii - desenhar contratos que lhes dêem os incentivos correctos para que persigam objectivos correlacionados com os lucros da empresa (minimização dos problemas de risco moral). Os gestores, quando correctamente mandatados para defender os interesses 


\section{A Empresa Baseada em (Novo) Conhecimento}

dos accionistas, sentirão problemas análogos com a selecção e monitorização das acções dos trabalhadores seus subordinados;

- A experiência pode também ser mobilizada para explorar o tema das fronteiras da empresa. Os participantes podem ainda questionar-se sobre se algumas tarefas não poderão ser desempenhadas mais eficientemente no exterior da empresa. Esta questão entronca na decisão de fazer dentro ou comprar fora, questão típica da teoria económica neo-institucionalista ou dos custos de transacção de Coase (1937) e Williamson (1985). De acordo com esta visão da coordenação da actividade económica, as operações serão realizadas dentro da empresa (hierarquia) até ao ponto em que os custos de realizar a operação sejam iguais aos custos de realizá-la fora em regime de outsourcing (mercado). De facto a empresa já tem à sua disposição folhas de papel que não foram produzidas por si. É possível imaginar que possa encomendar no mercado de produtos intermédios folhas de papel previamente dobradas ou mesmo já previamente cortadas. É também fácil imaginar que a empresa estabeleça contratos com empresas de distribuição para que os seus produtos apareçam nos seus pontos de venda. Para que os produtos transformados façam o trajecto desde a fábrica até ao ponto de venda onde finalmente os consumidores finais os podem comprar, a empresa pode subcontratar empresas de transportes em vez de assegurar ela mesma este serviço.

Outros aspectos tecnológicos. As observações efectuadas na experiência permitem ainda avançar a discussão sobre o conhecimento e a aprendizagem em vários outros sentidos:

- A especialização funcional leva a que um conjunto de tarefas simples sejam feitas repetidamente e que operários progridam na sua habilidade em levar a cabo cada um dos passos das operações que estão a seu cargo. Surgem deste modo hábitos de pensamento, como diria Thorstein Veblen. No entanto, os hábitos de pensamento e a sua evolução, a que Smith se referiu como aumento da destreza, não são exclusivamente redutíveis aos indivíduos. Como o conjunto de procedimentos necessários à produção tem uma componente interpessoal, uma vez que estes exigem a passagem de matérias em transformação e a partilha de informação entre os diversos especialistas, existe na empresa um conhecimento tácito de natureza colectiva. O conhecimento tácito é difícil de articular pelos seus detentores, uma vez que é gerado no contexto da acção produtiva normal e manifesta-se num conjunto de práticas interactivas de equipa que se estabelecem de forma rotineira na empresa. Este conhecimento que se encontra embutido nos procedimentos operacionais da empresa facilita a execução das múltiplas e complicadas operações associadas à normal actividade da empresa. Ou seja, as rotinas permitem à organização poupar energia e custos no processamento consciente de informação (Nelson e Winter, 1982), ou seja, e para utilizar o conceito de Herbert Simon, permitem poupar o recurso escasso que é a racionalidade limitada. Os agentes económicos têm um conhecimento imperfeito do que se passa à sua volta. À evolução deste conhecimento chamamos aprendizagem colectiva; 


\section{A Empresa Baseada em (Novo) Conhecimento}

- A generalidade das empresas são empresas multiproduto. No entanto, essa realidade está uma vez mais ausente do centro da análise dos livros de introdução à ciência económica. No cenário experimental que construímos não é difícil compreender que a produção de uma variedade de produtos pode surgir da mesma colecção de recursos. Por exemplo, produzir um livro que abre na vertical e não na horizontal não exigiria uma grande transformação do processo de produção. Seria até possível que a diminuição do volume de produção de uma das variedades, com a necessária perda de economias de escala, fosse compensada por uma forte procura da nova variedade do produto final. Quando a distância entre o produto original e a nova versão não é muito grande chamamos a esta estratégia diferenciação, quando a distância é mais significativa então estamos perante uma estratégia de diversificação. Estas estratégias fazem sentido quando se verifica aquilo a que comummente se designa por "sinergia". Mais precisamente, verificam-se economias de gama quando os custos agregados da produção conjunta de vários tipos de bens são menores do que a soma dos custos de os produzir separadamente. Estas economias surgem quando produtos diferentes partilham os mesmos recursos, muitas vezes subutilizados, e por isso têm custos conjuntos (Penrose, 1959);

- O facto das novas indústrias químicas e automóveis do início do século XX gerarem simultaneamente leques de produtos relacionados (derivados do petróleo, gamas de carros), que eram baseados nos mesmos processos capital-intensivos levou a que a se desenvolvessem economias de gama no seio de empresas gigantescas e diversificadas. Ao modo de organização destas empresas Chandler (1990) chamou "forma M" ou estrutura multidivisional, uma estrutura organizacional caracterizada por unidades de negócio devotadas a determinados ramos produtivos que respondiam a um mesmo quartelgeneral que regulava o funcionamento geral da empresa. No caso da nossa empresa experimental, é fácil imaginar que a empresa cresceria até ao máximo da sua rentabilidade, sendo que, ao abrir uma nova fábrica, esta poderia focar-se num outro tipo de produto. As duas fábricas seriam geridas por gestores de unidades de negócio e teríamos assim uma empresa com uma estrutura divisional, uma versão simplificada da estrutura multidivisional.

Em resumo, a teoria económica do produtor, tal como expressa nos livros introdutórios de microeconomia, é muito simples, talvez demasiado simples. A teoria convencional entende a empresa como uma função de produção, isto é, uma relação entre inputs e outputs, uma “caixa negra” cujo interior não é estudado. A visão básica da empresa é um agente atomístico representativo que produz bens homogéneos, com o objectivo único de maximizar o lucro num regime de concorrência perfeita. A empresa é um autómato sem criatividade, actor passivo que responde automaticamente à variação de preços relativos dados pelo mercado. Neste mundo, a empresa típica acede a conhecimento economicamente produtivo sem dificuldades (o conhecimento é equacionado a informação e a informação é tida como um bem público) e obtém os seus recursos a partir de um mercado de inputs que também funciona em concorrência perfeita. A empresa neoclássica é um dispositivo teórico que serve o propósito maior de explicar o aparecimento do equilíbrio 


\section{A Empresa Baseada em (Novo) Conhecimento}

geral nos mercados, daí o seu enfoque estático. Como qualquer teoria ou tentativa de explicação de uma realidade, esta abordagem tem várias limitações: a empresa representativa, una e indivisível, dotada de hiperracionalidade, etc. não corresponde à nossa compreensão da realidade.

O exercício proposto é revelador. A experimentação de uma fábrica, embora sendo desenhado para replicar o conceito estático de função de produção, permitiu, no entanto, abrir a caixa de Pandora da empresa inovadora. A função de produção representa uma dada forma de combinar os recursos para obter resultados possíveis e esperados. No entanto, o conhecimento sobre o que produzir e como produzir é influenciado pelos próprios actores. Foi possível detectar um conjunto de aspectos que a teoria convencional não trata, mas que são essenciais para compreender a natureza das empresas reais. A actividade produtiva é um fenómeno organizacionalmente complexo e necessariamente dinâmico. A empresa experimental gerou um conjunto de dados que dão crédito a novas visões teóricas, as quais se vêm desenvolvendo nas últimas décadas:

- A teoria da agência vem demonstrar que a empresa é uma molécula de interesses diferentes, possivelmente divergentes;

- A teoria neoinstitucionalista alerta para o facto de que a empresa não existe no vácuo; uma empresa renegoceia a cada instante a sua dimensão com o seu exterior;

- Os contributos de Nelson, Penrose, Simon, Winter, e de outros autores associados à escola evolucionista dirigem a nossa atenção para a ideia de que a empresa possui um princípio activo, i.e., a empresa é uma organização de recursos tangíveis e intangíveis que permite gerar produtos (bens e/ou serviços) que, por sua vez, representam a resolução de problemas com valor económico para os clientes.

É esta última linha de reflexão, de natureza cognitiva, que seguidamente nos interessará aprofundar. A próxima secção tenta fazer uma sistematização de ensaios de "nano-análise” da natureza inovadora das empresas (que se passa dentro das empresas inovadoras?) e proceder a uma inventariação dos padrões e tendências exibidos pelas empresas inovadoras (como apreciar a diversidade e a evolução dos vários sectores da economia?).

\section{O CONHECIMENTO E A APRENDIZAGEM NAS EMPRESAS}

\section{Recursos, Rotinas e Competências}

Sugere Edith Penrose (1995, pg. xi) que as empresas são colecções de recursos, aos quais os poderes administrativos dão um sentido comum. Estes recursos são activos tangíveis (e.g. equipamentos, instalações) 


\section{A Empresa Baseada em (Novo) Conhecimento}

ou intangíveis (e.g. conhecimentos técnicos, procedimentos eficientes, redes de contactos, reputação da marca, etc.) e são relativamente estáveis, acumulando-se lentamente ao longo do tempo. Para Penrose, as idiossincrasias de cada empresa radicam nos serviços que se extraem dos recursos e não nos recursos propriamente ditos. É, portanto, na capacidade de combinarem recursos de maneira única que as empresas se distinguem entre si. A essência desta capacidade é algo que deve ser procurado nas "entranhas” das empresas, isto é, importa saber como as empresas se organizam para tirar partido do conhecimento que possuem.

Rotinas são padrões de comportamento colectivo, automático, recorrente e previsível (Nelson e Winter, 1982, pg. 14). As rotinas funcionam como repositórios da experiência interpretada acumulada ao longo do tempo nas empresas, fora delas existe incerteza genuína (Dosi e Marengo, 1999; Fagerberg, 2003; Winter, 1993). As rotinas actuam como mecanismos integradores de conhecimentos individuais e de práticas interpessoais. Rotinas representam inércia e memória organizacional; contudo, mutações verificadas no modo normal de efectuar as actividades das rotinas podem ser concebidas como aprendizagem. O conhecimento que as rotinas representam é aperfeiçoado pela repetição e pelo acumular de experiência. Interessa também compreender as rotinas que, dentro na empresa, estão especializadas na promoção da mudança interna e na adaptação a alterações na envolvente externa, isto é, a produção de novo conhecimento no departamento de I\&D ou afins. A evolução das rotinas é lenta, reflectindo uma aprendizagem colectiva resultante de inferências da história. A aprendizagem informal e a experimentação explícita são tanto mais importantes quanto traduzem as vias pelas quais as organizações desenvolvem os seus saberes, ficando em condições de introduzirem inovações e crescerem nos mercados em que já estão instaladas ou entrarem em mercados novos.

São as competências que definem o tipo de problemas com valor para os clientes efectivos e potenciais que as empresas são capazes de resolver (Chandler, 1992; Nonaka e Takeushi, 1995). A sobrevivência e o sucesso de uma empresa depende da capacidade de procurar um espaço no mercado e preenchê-lo. Os produtos são, assim, manifestações temporárias das competências empresariais (Pralahad e Hamel, 1990; Lawson, 1999). As competências podem ser vistas como propriedades emergentes do nexo de recursos e rotinas que compõem o interior da empresa; as empresas são assim uma realidade estruturada. As competências da empresa definem-se a todo o momento pelos sucessivos reencontros entre as capacidades, i.e., o potencial de acção inscrito nas rotinas, e o mercado, entendido aqui como mecanismo selectivo de soluções comercialmente viáveis.

Deste modo, as competências resultam de uma construção parcial que depende da estratégia e da história das empresas mas, também, do resultado incerto dos seus confrontos com clientes e empresas concorrentes. O ambiente comercial, tecnológico e institucional impõe padrões competitivos, aos quais as organizações têm de saber responder sob pena de desaparecerem. Contudo, as competências evoluem lentamente uma vez 


\section{A Empresa Baseada em (Novo) Conhecimento}

que a busca de novas soluções é feita sobretudo na orla daquilo que já se conhece (i.e. localised learning) e depende do percurso de aprendizagem percorrido no passado (i.e. path dependence). Em virtude da sua estabilidade, as competências podem também constituir armadilhas se o ambiente selectivo mudar rapidamente (Leonard-Barton, 1998).

As competências têm uma natureza tácita, cumulativa ao longo do tempo, pelo que influenciam a capacidade de as empresas inovarem em determinadas direcções e não noutras. O "saber fazer” e "por que fazer” é impossível ou dispendioso de traduzir por símbolos. A implicação é que a transferência de tecnologia, bem como a imitação, são difíceis de efectuar sem exposição continuada ou sem a transferência de indivíduos ou equipas. Competências específicas explicam, assim, a persistência de vantagens competitivas entre empresas e a heterogeneidade nas populações empresariais. Em inovação não existem empresas representativas marshallianas, i.e., pequenos agentes produtivos atomísticos que fazem o seu melhor para se ajustarem às variações dos preços decorrentes do livre funcionamento dos mercados. O saber fazer é o que distingue as empresas nos mercados e "saber fazer o novo" confere às organizações uma oportunidade para reescrever as regras do contexto em que se movem. Assim, as competências não têm necessariamente um carácter estático, uma vez que podem incluir rotinas especificamente vocacionadas para subverterem os procedimentos instalados na organização (Pavitt, 2002). Exemplos de rotinas inovadoras são as actividades de investigação, de monitorização de mercado e de articulação com o exterior. Estas rotinas são aquelas que introduzem novidade no statu quo organizacional e que mais tarde podem ou não ser testadas comercialmente. Por exemplo, a actividade de I\&D é uma maneira rotinizada de procurar novos problemas e gerar novas alternativas. Devido à sua natureza essencialmente dinâmica e à sua co-evolução com as pressões do ambiente, chamaremos competências dinâmicas a uma articulação de rotinas que inclua rotinas inovadoras (Teece e Pisano, 1994).

\section{Características das Empresas Inovadoras}

As competências capazes de sustentar a descoberta continuada de novas soluções técnicas são mais difíceis de imitar que uma dada tecnologia em particular. A inovação é sempre uma actividade incerta, um salto no desconhecido. A incerteza é tecnológica, porque uma invenção raramente surge sem problemas, carece sempre de desenvolvimento e teste. A incerteza também é comercial, uma vez que o novo atributo, o design ou o preço nem sempre persuadem os clientes potenciais a adoptarem a nova proposta. Inovar significa necessariamente falhar e não optimizar. O importante, todavia, é aprender com os erros. Um compromisso com uma estratégia inovadora para ser bem sucedido depende de um conjunto de dimensões as quais se apresentam abaixo: 


\section{A Empresa Baseada em (Novo) Conhecimento}

Capacidade de invençẫo. A instituição da I\&D e de rotinas vocacionadas para a busca explícita de novas e melhores tecnologias são provavelmente a base mais eficaz de competências dinâmicas (Nelson, 1991). No século XX, os esforços de descoberta e invenção tornaram-se uma tarefa de instituições especializadas. As actividades de pesquisa básica e de desenvolvimento experimental profissionalizaram-se e começaram a ser responsáveis por uma parte crescente dos novos produtos e processos que definem as sociedades contemporâneas (Freeman e Soete, 1997, pg.5). No conjunto dos países da OCDE, o sector privado domina a execução da I\&D, tendo as despesas das empresas no total da I\&D chegado a 63,9\% no ano 2000 (OCDE, 2002). Face à média europeia, que se situa nos 65,5 \% em 2000, abaixo dos EUA (75\%) e do Japão (71\%), Portugal registava em 2001 um padrão inverso com um peso de apenas 32\% de despesas privadas na I\&D total (Comissão Europeia 2002, p. 25).

Capacidade de absorção. O investimento em novo saber economicamente útil permite adicionalmente identificar, reconhecer o valor e internalizar informação técnica produzida fora das fronteiras da organização (Cohen e Levinthal, 1990). A I\&D constitui, então, um indicador sobre a capacidade de as organizações aprenderem com a investigação relevante que se vai desenvolvendo, ficando aptas para descodificarem informação técnica produzida por universidades, centros tecnológicos e laboratórios públicos, bem como aproveitarem as externalidades positivas que resultam da investigação privada levada a cabo por outras empresas, concorrentes ou não.

Activos complementares. A excelência técnica não é suficiente para garantir o sucesso da inovação; a empresa deve igualmente garantir um conjunto de activos e competências que apoiem a chegada bem sucedida da inovação ao mercado como sejam, por exemplo, uma capacidade de produção e de distribuição eficientes e com controlo de qualidade (ver figura 3). Um dos problemas detectados na estrutura interna das empresas portuguesas é justamente um fraco desenvolvimento organizacional, em particular das competências de marketing (Salavisa Lança, 2000).

Figura 3. Activos necessários à comercialização da invenção 


\section{A Empresa Baseada em (Novo) Conhecimento}

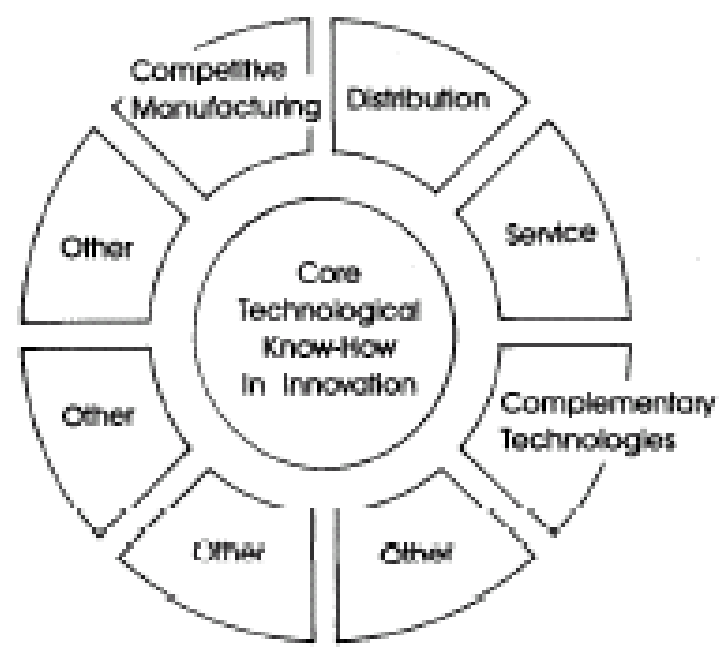

Fonte: Teece (1986).

Interacção produtor-utilizador. Os utilizadores mais exigentes e sofisticados constituem uma fonte insubstituível, eficaz e pouco dispendiosa de ideias aplicáveis (von Hippel, 1988). O processo que leva à inovação tem tanto de colaboração como de competição. A aprendizagem é um processo social e interactivo, em que as ligações envolvendo partilha informal de informações permitem reduzir a incerteza (Lundvall, 1988). Dado que é frequente serem os utilizadores, e não os engenheiros, os primeiros a detectar insuficiências, a história demonstra que os inovadores bem sucedidos passam por serem "bons ouvintes" (Petroski, 1994, p. 40).

\section{Taxonomias de Empresas Inovadoras}

As taxonomias são tentativas sempre inacabadas, classificação de objectos por via indutiva. O objectivo é simplificar a variabilidade que caracteriza a realidade. A sua base empírica distingue estes exercícios de classificação das tipologias. A prática de classificação de empresas por categorias mais ou menos inovadoras constitui um desafio delicado, uma vez que nesta matéria, provavelmente mais do que em outras, as taxonomias serão ferramentas de análise necessariamente imperfeitas e em permanente desactualização.

Os esforços de criar um esquema de classificação começaram por fazer-se com base nas estatísticas de I\&D, variável para a qual a produção de estatísticas é mais completa e internacionalmente comparável desde a década de 1960. A OCDE divide a indústria transformadora em quatro grandes grupos, conforme a taxa de esforço revelada nas despesas de I\&D (ver quadro 2). Embora seja útil como primeira abordagem, a I\&D nem sempre é um indicador fiável da criação de novo conhecimento tecnológico (ou organizacional). Em primeiro lugar, esta abordagem penaliza sectores que não registam formalmente os seus esforços de pesquisa como I\&D, mas antes como actividades de design, engenharia de produto, etc. Estes são sectores como os produtores de equipamento mecânico. Em segundo lugar, a classificação não cobre os sectores de serviços, os quais que constituem a maior parte do produto e do emprego nas economias mais avançadas e inovadoras. 


\section{A Empresa Baseada em (Novo) Conhecimento}

Em terceiro lugar, os sectores "tradicionais" são muitas vezes mais activos do que a designação de "baixa intensidade tecnológica” pode levar a crer. Veja-se o caso do sector do calçado, do vinho ou da cortiça em Portugal. Apesar de todos os problemas, a classificação da OCDE continua a ser muito utilizada para fins de política pública embora esteja cada vez mais a perder a sua utilidade analítica (Smith, 2004).

Quadro 2. Classificação de indústrias por intensidade tecnológica (Despesas em I\&D/VAB)

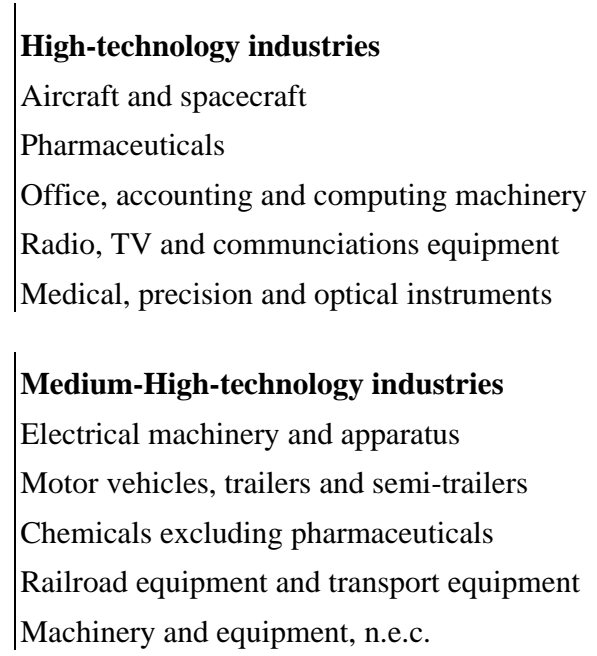

\begin{tabular}{c|l}
$>5 \%$ & Medium-Low-technology industries \\
10,3 & Building and repairing of ships and boats \\
10,5 & Rubber and plastics products \\
7,2 & Coke, refined petroleum pcts and nuclear fuel \\
7,4 & Other non-metallic mineral products \\
9,7 & Basic metals and fabricated metal products
\end{tabular}

[3\% 5\%] Low-technology industries

3,6 Manufacturing, Recycling

3,5 Wood, pulp/paper pts, printing and publishing

2,9 Food products, beverages and tobacco

3,1 Textiles, textile products, leather and footwear
[0,9\%; 0,5\%]

1,0

1,0

0,4

0,8

0,6

$<0,9 \%$

0,5

0,4

0,3

0,3

Total manufacturing 2,6\%

Fonte: OCDE (2003).

Um esforço alternativo de classificação de empresas inovadoras foi desenvolvido por Pavitt (1984). Esta taxonomia, que se revelou muito robusta ao exame empírico, é mais subtil que a anterior e permite diferenciar os sectores consoante as fontes de inovação mais relevantes. Este esquema permite ainda distinguir implicações quanto às estratégias de inovação mais prudentes em cada caso. Porém, a taxonomia pouco nos diz quanto ao sector dos serviços (ver quadro 3).

Quadro 3. Taxonomia de Pavitt

\begin{tabular}{|c|c|c|c|c|c|}
\hline & $\begin{array}{l}\text { Supplier- } \\
\text { Dominated }\end{array}$ & $\begin{array}{l}\text { Scale- } \\
\text { intensive }\end{array}$ & $\begin{array}{l}\text { Information- } \\
\text { intensive }\end{array}$ & $\begin{array}{l}\text { Science } \\
\text { based }\end{array}$ & $\begin{array}{l}\text { Specialised } \\
\text { suppliers }\end{array}$ \\
\hline Sectores & $\begin{array}{l}\text { Agricultura } \\
\text { Serviços } \\
\text { Indústrias } \\
\text { tradicionais }\end{array}$ & $\begin{array}{l}\text { Electrodomésticos } \\
\text { Automóvel } \\
\text { Construção civil }\end{array}$ & $\begin{array}{l}\text { Banca e Seguros } \\
\text { Retalho } \\
\text { Operadores de } \\
\text { viagens }\end{array}$ & $\begin{array}{l}\text { Electrónica } \\
\text { Biotecnologia } \\
\text { Farmacêutica } \\
\text { TIC }\end{array}$ & $\begin{array}{l}\text { Máquinas } \\
\text { Software } \\
\text { Instrumentos } \\
\text { "Aviónicos" }\end{array}$ \\
\hline $\begin{array}{l}\text { Fontes de } \\
\text { inovação }\end{array}$ & $\begin{array}{l}\text { Fornecedores } \\
\text { Dept. de } \\
\text { operações }\end{array}$ & $\begin{array}{l}\text { Engenharia de } \\
\text { processos } \\
\text { Produção }\end{array}$ & $\begin{array}{l}\text { Dept. informática } \\
\text { e sistemas } \\
\text { Fornecedores }\end{array}$ & $\begin{array}{l}\text { I\&D } \\
\text { Investigação } \\
\text { universitária }\end{array}$ & $\begin{array}{l}\text { Dept. de design } \\
\text { Utilizadores } \\
\text { avançados }\end{array}$ \\
\hline $\begin{array}{l}\text { Estra- } \\
\text { tégias }\end{array}$ & $\begin{array}{l}\text { Marketing } \\
\text { Utilização de } \\
\text { TIC }\end{array}$ & $\begin{array}{l}\text { Eficiência operacional } \\
\text { Distribuição } \\
\text { Integração gradual de }\end{array}$ & $\begin{array}{l}\text { Melhoria na } \\
\text { prestação do } \\
\text { serviço } \\
\text { Simplificação de }\end{array}$ & $\begin{array}{l}\text { Produtos intensivos } \\
\text { em tecnologia } \\
\text { Exploração da } \\
\text { ciência básica }\end{array}$ & $\begin{array}{l}\text { Monitorar e } \\
\text { responder às } \\
\text { necessidades dos } \\
\text { clientes }\end{array}$ \\
\hline
\end{tabular}




\section{A Empresa Baseada em (Novo) Conhecimento}

\begin{tabular}{|l|l|l|l|l|}
\hline $\begin{array}{l}\text { Resposta rápida } \\
\text { aos clientes }\end{array}$ & novas tecnologias & $\begin{array}{l}\text { operações } \\
\text { Utilização de } \\
\text { TIC }\end{array}$ & $\begin{array}{l}\text { Integração } \\
\text { gradual de novas } \\
\text { tecnologias }\end{array}$ \\
\hline
\end{tabular}

Fonte: Adaptado de Tidd et al. (2001).

A diversidade no sector dos serviços também é grande. Medir o desempenho inovador torna-se ainda mais difícil do que no caso da indústria, dado que a actividade consiste na produção de produtos intangíveis, muitas vezes consumidos no próprio acto da produção. Isso não quer dizer que os serviços não introduzam inovações no produto final ou modifiquem o modo como chegam aos clientes. Serviços como a banca foram sectores pioneiros na utilização inovadora de tecnologias de informação e comunicação. Em muitos serviços, no entanto, o conhecimento técnico é indispensável à criação e manutenção de vantagens competitivas. O quadro 4 apresenta uma tentativa de diferenciar os serviços assumindo que há uma correlação entre a actividade de processamento de informação e o recurso a conhecimentos sofisticados, inclusivamente de base científica.

Quadro 4. Intensidade informacional dos serviços

\begin{tabular}{|l|}
\hline Serviços de baixa intensidade informacional \\
Comércio grossista e retalhista \\
Transportes e turismo \\
Aluguer e arrendamento \\
Segurança e limpeza \\
Ensino básico e secundário \\
Saneamento, higiene e veterinária \\
\hline Serviços de alta intensidade informacional \\
Comunicações postais e telecomunicações \\
Actividades financeiras \\
Consultoria e informática \\
Ensino superior \\
Comunicação social \\
Serviços de saúde
\end{tabular}

Fonte: Adaptado de Godinho et al. (2003), com base em elementos de Murteira et al. (2001)

\section{Tendências Recentes na Organização da Inovação}




\section{A Empresa Baseada em (Novo) Conhecimento}

Seguidamente apresenta-se um conjunto de tendências que emergem no último quartel do século XX, as quais permitiram compreender melhor o papel das organizações na transição para uma sociedade baseada no conhecimento. A inovação escreve na história económica e industrial uma narrativa complexa, feita de conflitos e cooperações, e sempre de desfecho imprevisível. Sabendo que não é profícuo tentar prever sobre para onde vamos (neste aspecto diz-se que os economistas existem para que os meteorologistas façam boa figura), não é neutro para a nossa capacidade de antecipação inquirir sobre por onde estamos a ir. Sugerimos que as três tendências (inter-relacionadas) que abaixo se identificam serão forças que marcarão a mudança tecnológica e institucional. O modo como se cruzam mutuamente e se relacionam com outros factores socioeconómicos permanece, no entanto, um trabalho para os historiadores do futuro:

Empresas multitecnologia. O estudo das maiores empresas industriais empresas do mundo revelou a existência de várias trajectórias tecnológicas no seu portfolio de saberes (Granstrand e S. Sjölander, 1990; Patel e Pavitt, 1994; Cantwell et al., 2004). Este facto estilizado, com especial incidência no último quartel do século passado, estará relacionado com a revolução das tecnologias de informação e das biotecnologias (Mendonça, 2003). A razão das grandes empresas inovadoras saberem mais do que fazem está sobretudo relacionada com o papel que desempenham de integradoras de sistema produzidos por outras empresas mais pequenas no seu cinturão de fornecedores (Brusoni et al., 2001). Mais conhecimento aumenta a sua capacidade de coordenação na sua rede de parceiros, concorrentes e instituições de apoio (Mendonça, 2004). Nesse caso a grande empresa, que surgiu com a segunda revolução industrial e se impôs uma instituição económica incontornável no século XX, pode estar a atravessar um período de mudança sem paralelo que irá marcar as actividades empresariais inovadoras no corrente século.

Redes inovadoras. Nenhum inovador é uma ilha. Enquanto forma de governança, as redes tornaram-se mais centrais para geração de novas tecnologias, uma tendência que se tem manifestado na multiplicação de alianças, consórcios, parcerias, e colaborações informais nas últimas décadas. Esta tendência, que coloca novos desafios à estratégia das empresas, está claramente associada às novas tecnologias da nova revolução tecnológica (Hagedoorn, 2002). As redes inter-organizacionais de investigação desempenham um papel catalítico no desenrolar do processo de inovação (Powell e Grodall, 2004). Organizar inovação significa cada vez mais orquestrar um conjunto distribuído de competências. Esta tendência implica que as competências sociais ou relacionais serão cada vez mais importantes para a gestão da inovação, à medida que as fronteiras internas e externas das empresas se diluem. A incidência deste fenómeno de organização industrial no caso português permanece largamente indocumentada. Num dos raros estudos sobre cooperação interempresarial, Carvalho (2003) observou que a falta de empenhamento dos parceiros, a fraca cultura de interacção e a falta de capacidade tecnológica e financeira constituem os principais obstáculos à participação de PMEs portuguesas em alianças de I\&D, mesmo quando apoiadas por programas públicos. 


\section{A Empresa Baseada em (Novo) Conhecimento}

Örganizaçôes virtuais. As tecnologias de informação e comunicação que hoje conhecemos bem (Internet, telefonia portátil, etc.) permitem aos indivíduos e às empresas organizarem as suas actividades, prescindindo muitas vezes da co-localização para a resolução de problemas. Em muitos casos, o prosseguimento das operações nas empresas é já feita com base em projectos sucessivos em torno dos quais se vão configurando diferentes equipas (Paoli e Prencipe, 2003); nestes casos a informática terá um papel em armazenar a memória do grupo. O recurso a vias online e/ou wireless permite às empresas coordenarem os seus compromissos com outras organizações de um modo flexível e organizado. Numa esfera em grande parte externa às empresas, a comunidade globalizada de programadores, congregada (virtualmente) em torno do projecto Open Source/Software Libre, ilustra o poder da invenção colectiva descentralizada (Dalle et al., 2002).

\section{CONCLUSÕES}

As empresas enquanto entidades envolvidas na busca sistemática de soluções para novos e velhos problemas são objectos de investigação cada vez mais interessantes. Ao mesmo tempo, são organizações cada vez mais difíceis de gerir. A noção de optimização não providencia uma explicação realista da actividade concreta das empresas. A incerteza impera. Importa assim compreender como a inovação contribui para a turbulência dos mercados e permite também uma melhor adaptação à mudança.

A competição é uma luta incessante pela superioridade relativa das propostas de valor que são sugeridas ao mercado. Schumpeter credita os ensinamentos económicos de Karl Marx como tendo sido os primeiros a sublinhar a natureza qualitativa inerente ao desenrolar da vida económica. Schumpeter herda uma visão dinâmica contida em palavras como as seguintes publicadas pela primeira vez em 1848:

Esta transformação contínua da produção, este constante abalo de todo o sistema social, esta agitação e esta insegurança perpétuas distinguem a época burguesa de todas as precedentes. (Marx e Engels, 1848, p. 39)

Estudar a inovação implica não só um reforço da atenção dada à mudança, como também à variedade, intra e entre empresas. Os conceitos de rotinas e competências ajudam a explicar por que razão os sectores são heterogéneos e por que a variabilidade de desempenhos entre empresas é persistente (vantagens competitivas sustentáveis). As rotinas permitem poupar custos de recolha, processamento e tratamento de informação. A mutação de rotinas e a aprendizagem de competências (inovação) é um processo colectivo que depende do percurso histórico específico da organização como, por exemplo, do seu património cognitivo e da sua interacção com o ambiente selectivo. Conjugações de rotinas permitem gerar produtos (bens, serviços) por um preço. Por outras palavras, de combinações de rotinas emergem competências, isto é, a capacidade 


\section{A Empresa Baseada em (Novo) Conhecimento}

organizacional de combinar conhecimentos e outros recursos na resolução de problemas técnicos com valor económico para os clientes. As competências são dinâmicas quando implicam a capacidade de gerar e implementar mudanças economicamente úteis num ambiente complexo e dinâmico. São específicas às empresas, parcialmente tácitas e difíceis de replicar. São ainda cumulativas e progridem passo a passo quanto ao seu desenvolvimento.

Sendo que a inovação está na base de vantagens competitivas sustentáveis, o desafio está em gerar competências dinâmicas que permitam à empresa apresentar soluções inovadoras aos novos e velhos problemas dos clientes. No início do novo século, não faltam questões sobre a organização das actividades inovadoras: Estarão as empresas a perder terreno para novas estruturas organizacionais mais porosas, descentralizadas e interactivas? Como está a evoluir a divisão de trabalho cognitivo entre grandes empresas, pequenas empresas e redes de inovadores? Que competências sociais necessitam as organizações de desenvolver para alimentar processos inovadoras e extrair valor do novo conhecimento criado? Estas e outras questões prometem animar as agendas dos investigadores e dos decisores nos próximos anos. 


\section{BIBLIOGRAFIA}

Abramovitz, M.A. (1956), "Resources and output trends in the United States since 1870", American Economic Review, Vol. 46, pp. 5-23.

Asheim, B. e M. Gertler (2004), "Regional innovation systems and the geographical foundations of innovation”, in J. Fagerberg, D.C. Mowery e R.R. Nelson (Coord.), The Oxford Handbook of Innovation, Oxford University Press, pp. 291-317.

Arthur, W.B. (2002), "Is the Information Revolution Over? If history is a guide, it is not”, Business 2.0, http://www.business2.com/articles/mag/0,1640,37570,00.html.

Brusoni, S., A. Prencipe e K. Pavitt (2001), "Knowledge specialization, organizational coupling and the boundaries of the firm: Why do firms know more than they make?”, Administrative Science Quarterly, Vol. 46., pp. 597-621.

Cantwell, J., A. Gambardella e Ö. Grandstrand (Coord.) (2004), The Economics and Management of Technological Diversification, London: Routledge.

Carvalho, A. (2003), "PMEs portuguesas em alianças de I\&D no âmbito do programa CRAFT: Condições iniciais, problemas de cooperação e resultados”, Notas Económicas, Dezembro, pp. 46-64

Castellacci, F., S. Grodal, S. Mendonça e M. Wibe (2005), “Advances and challenges in innovation studies”, Journal of Economic Issues, Vol. 39, No. 1, pp. 91-121.

Castells, M. (2000), The Rise of the Network Society, revised edition, Blackwell Publishers: Oxford, and Malden, MA.

Chandler, A. (1990), Scale and Scope: The Dynamics of Industrial Capitalism, Belknap Press.

Chandler, A. (1992), “Organizational capabilities and the economic history of the industrial enterprise”, Journal of Economic Perspectives, Verão, pp. 79-100.

Coase, Ronald (1937), “The nature of the firm”, Economica, Vol. 4, pp. 386-405.

Cohen, W.M. e D.A. Levinthal (1990), “Absorptive capacity: a new perspective on learning and innovation”, Administrative Science Quarterly, Vol. 35, pp. 128-52. 


\section{A Empresa Baseada em (Novo) Conhecimento}

Comissão Europeia (2002), Towards a European Research Area-- Key 2002 Science, Technology and Innovation. Bruxelas: Comissão Europeia.

Dalle, J.-M., P.A. David e W. E. Steinmueller, (2002), “An Agenda for Integrated Research on the Economic Organization and Efficiency of OS/FS Software Development," Proceedings of the NSF/CISE \& EC/IST Workshop on Advancing the Research Agenda on Free / Open Source Software, Bruxelas, 14th October 2002.

Davis, D.D. e C. Holt (1992), Experimental Economics, Princeton: Princeton University Press.

Diamond, J. (1998), Guns, Germs and Steel: A Short History of Everybody for the Last 13000 Years, London: Vintage

Dosi, G. (1982), “Technological paradigms and technological trajectories”, Research Policy, Vol. 11, pp. $147-62$.

Dosi, G., C. Freeman, R.R. Nelson, G. Silverberg e L. Soete (Coord.) (1988), Technical Change and Economic Theory. London: Pinter.

Dosi, G. e L. Marengo (1994), "Some elements of an evolutionary theory of organizational competences", in R. England (ed.), Evolutionary Concepts in Contemporary Economics, Ann Arbor: University of Michigan Press.

Dosi, G. e L. Marengo (1999), "The co-evolution of technological knowledge and corporate organizations", in A.Gambardella e F. Malerba (eds.), The Organization of Economic Innovation in Europe, Cambridge: Cambridge University Press, pp. 15-23.

Edquist, C. (2004), “Systems of innovation - perspectives and challenges”, in J. Fagerberg, D.C. Mowery e R.R. Nelson (Coord.), The Oxford Handbook of Innovation, Oxford University Press, pp. 181-208.

Ekelund, R.B. e R.F. Hérbert (1990), A History of Economic Theory and Method, McGraw-Hill International Editors.

Fagerberg, J. (2003), "Schumpeter and the revival of evolutionary economics: an appraisal of the literature”, Journal of Evolutionary Economics, Vol. 13, pp. 125-59.

Fagerberg, J. (2004), “Innovation: A Guide to the Literature”, in J. Fagerberg, D.C. Mowery e R.R. Nelson (Coord.), The Oxford Handbook of Innovation, Oxford University Press, pp. 1-26.

Fagerberg, J., D.C. Mowery e R.R. Nelson (Coord.) (2004), The Oxford Handbook of Innovation, Oxford University Press.

Fagerberg, J., P. Guerrieri e B. Verspagen (eds.) (1999), The Economic Challenge for Europe: Adapting to Innovation-based Growth, Aldershot: Edward Elgar

Freeman, C. (1982), The Economics of Industrial Innovation, London: Francis Pinter, $2^{\mathrm{a}}$ edição.

Freeman C. (1987), Technology Policy and Economic Performance: Lessons from Japan, London: Pinter.

Freeman, C. (2002), "Continental, national and sub-national innovation systems - complementarity and economic growth”, Research Policy, Vol. 31, pp. 191-211.

Freeman, C. e F. Louçã (2001), As Time Goes By: The Information Revolution and the Industrial Revolution in Historical Perspective, Oxford: Oxford University Press. 
Freeman, C. e L. Soete (1997), The Economics of Industrial Innovation, $3^{\mathrm{a}}$ edição., Londres e Washington: Pinter.

Granstrand, Ö. e S. Sjölander (1990), “Managing innovation in multi-technology corporations”, Research Policy, Vol. 19, pp. 35-60.

Godinho, M.M., S. Mendonça e T.S. Pereira (2003), "Ritmos e direcções da ciência e tecnologia em Portugal", apresentado em "Inovação Tecnológica e Globalização: Implicações para os Países de Desenvolvimento Intermédio, Lisboa, ISCTE, 23-24 de Outubro, a ser publicado em I. Salavisa Lança, W. Rodrigues e S. Mendonça (Coord.), Inovação e Globalização: Implicações para os Países de Desenvolvimento Intermédio.

Godinho, M.M., T.S. Pereira, V.C. Simões, S. Mendonça e V. Sousa (2003), Utilização de Propriedade Industrial: Um Estudo sobre Inovação em Portugal, Lisboa: INPI, Ministério da Economia.

Hagedoorn, J. (2002), "Inter-firm R\&D partnerships: an overview of major trends and patterns since 1960", Research Policy, Vol. 31, pp. 477-92.

Hagel, J.H. e A.E. Roth (eds) (1995), The Handbook of Experimental Economics, Princeton: Princeton University Press.

Kagel, J.H. e A. Roth (Coord.) (1995), Handbook of Experimental Economics, New Jersey: Princeton University Press.

Kline, S., \& Rosenberg, N. (1986). “An overview of innovation”, in R. Landau e N. Rosenberg (eds.), The Positive Sum Strategy, Washington: National Academy Press.

Landes, D. (1969), The Unbound Prometheus: Technological change and industrial development in Western Europe from 1750 to the Present, Cambridge University Press, Cambridge (USA).

Lawson, C. (1999), “Towards a competence theory of the region”, Cambridge Journal of Economics, Vol. 23, No. 2, pp. 151-66.

Leonard-Barton, D. (1998), Wellsprings of Knowledge: Building and Sustaining the Sources of Innovation, Harvard Business School Press.

Levitt, B. and J.G. March (1988), “Organizational learning”, Annual Review of Sociology, 14.

Lundvall, B. -Å. (1988), "Innovation as an interactive process: from user-production interaction to the national system of innovation”, in G. Dosi et al. (Coord.), Technical change and economic theory, Londres: Pinter Publishers.

Lundvall, B.-Å. (Coord.) (1992), National Systems of Innovation: Towards a Theory of Innovation and Interactive

Learning, Londres: Pinter Publishers.

Malerba, F. (2004), "Sectoral systems: How and why innovation differs across sectors", in J. Fagerberg, D.C. Mowery and R.R. Nelson (Coord.), The Oxford Handbook of Innovation, Oxford University Press, pp. 340-406.

Mamede, R.P. (2004), “On the concept of routines in the contemporary evolutionary approach to economics”, Economia Global e Gestão, Vol. IX, pp.39-51. 


\section{A Empresa Baseada em (Novo) Conhecimento}

Marx, K. e F. Engels (1878), O Manifesto do Partido Comunista, Editorial Estampa, s/ data.

Mendonça, S. (2003), "News out of the old: The evolving technological incoherence of the world's largest companies”, in J.F. Christensen e P. Maskell (Coord.), The Industrial Dynamics of the New Digital Economy, Cheltenham, UK: Edward Elgar, pp. 121-150.

Mendonça, S. (2004), "Large companies from all sectors patenting in ICT: Is there a link between corporate technological diversification and the Information Revolution?”, in J. Cantwell, A. Gambardella e Ö. Grandstrand (eds), The Economics and Management of Technological Diversification, Londres: Routledge.

Mendonça, S., M.M. Godinho and T.S. Pereira (2004), “A note on Portuguese inventors”, policopiado.

Mokyr, J. (2002), The Gifts of Athena: Historical Origins of the Knowledge Economy, Princeton: Princeton University

Press.

Murteira, M., I. Nicolau, V. Mendes, A. Martins (2001), Serviços Informacionais e Transição para a Economia do Conhecimento em Portugal, Lisboa, GEPE-ME/IAPMEI.

Nelson, R.R. (1991), “Why firms differ, and how does it matter?”, Strategic Management Journal, pp. 6174.

Nelson, R.R., e S. Winter (1982), An Evolutionary Theory of Economic Change, Cambridge, Mass.: Belknap.

Nonaka, I. e Takeuchi, H (1995), The Knowledge Creating Company, Nova Iorque: Oxford University Press.

OCDE (2003), STI Outlook, OCDE: Paris.

Paoli, M. e A. Prencipe (2003), "Memory of the organisation and memories within the organisation", Journal of Management and Governance, Vol. 7, pp. 145-62.

Patel, P. e K. Pavitt (1994), “Technological competencies in the world's largest firms: Characteristics, constraints and scope for managerial choice”, STEEP Discussion Paper no. 13.

Patel, P. e K. Pavitt (1995), "Patterns of economic activity: Their measurement and interpretation”, in P. Stoneman (Coord.), Handbook of Economics of Innovation and Technical Change, Oxford: Blackwell, pp. 14-51.

Pavitt, K. (1984), "Sectoral patterns of technical change: Towards a taxonomy and a theory", Research Policy, Vol. 13, pp. 343-73.

Pavitt, K. (1998), “Technologies, products and organisation in the innovating firm: What Adam Smith tells us and Joseph Schumpeter doesn’t”, Industrial and Corporate Change, vol. 7, no. 3, pp. 433-52.

Pavitt, K. (2002), "Innovating routines in the business firm: what corporate tasks should they be accomplishing?”, Industrial and Corporate Change, Vol. 11, No. 1, pp. 117-133.

Pavitt, K. e W.E. Steinmueller (2001), “Technology in corporate strategy: change, continuity, and the information revolution”, in A. Pettigrew, H. Thomas e R. Whittington (Coord.), Handbook of Strategy and Management, Londres: Sage Publications, pp 344-72.

Penrose, E. (1957, 1995), The Theory of the Growth of the Firm, 3ª edição, Oxford University Press.

Pérez, C. (2002), Technological Revolutions and Finance Capital, Cheltenham, UK: Edward Elgar. 
Petroski, H. (1994), The Evolution of Useful Things, Vintage Books: New York.

Powell, W. e S. Grodal (2004), “Networks of innovators”, in J. Fagerberg, D.C. Mowery and R.R. Nelson (Coord.), The Oxford Handbook of Innovation, Oxford University Press, pp. 56-85.

Prahalad, C.K. e G. Hamel (1990), "The core competence of the corporation”, Harvard Business Review, Maio-Junho, pp. 79-91.

Rosenberg, N. (1982), Inside the Black Box: Technology and Economics, Cambridge: Cambridge University Press.

Rosenberg, N. (1994), Exploring the Black Box, Cambridge: Cambridge University Press.

Roth, A. (1995), "Introduction to experimental Economics”, in J.H. Kagel \& A. Roth (Coord.), Handbook of Experimental Economics, New Jersey: Princeton University Press.

Salavisa Lança, I. (org.) (2000), “A indústria portuguesa”, in I. Salavisa Lança (Coord.), A Indústria Portuguesa: Especialização Internacional e Competitividade, Oeiras, Celta Editora, pp. 61-79.

Smith, A. (1776), Riqueza das Nações, publicado em 1980, Lisboa: Fundação Calouste Gulbenkian.

Smith, K. (2004), "Measuring innovation”, in J. Fagerberg, D.C. Mowery and R.R. Nelson (Coord.), The Oxford Handbook of Innovation, Oxford University Press, pp. 148-78.

Solow, R.M. (1957), “Technical progress and the aggregate production function”, Review of Economics and Statistics, Vol. 39, 312-20.

Teece, .D. (1986), "Profiting from technological innovation: Implications for integration, collaboration, licensing and public policy”, Research Policy, Vol. 15, pp. 285-305.

Teece, D. e G. Pisano (1994), “The dynamic capabilities of firms: an introduction”, Industrial and Corporate Change, Vol. 3, N. 3, pp. 537-56

Tidd, J., Bessant, J. e Pavitt, K. (2001), Managing Innovation, Chichister, John Wiley \& Sons, 2ª edição.

Verspagen, B. (2004), “Innovation and economic growth”, in J. Fagerberg, D.C. Mowery e R.R. Nelson (Coord.), The Oxford Handbook of Innovation, Oxford University Press, pp. 487-513.

von Hippel, E. (1988), The Sources of Innovation, Nova Iorque: Oxford University Press

von Tunzelmann, N. (1995), Technology and Industrial Progress: The Foundations of Economic Growth, Aldershot: Edward Elgar.

von Tunzelmann, N. (2003), "Historical coevolution of governance and technology in the industrial revolutions”, Structural Change and Economic Dynamics, Vol. 14, Issue 4, pp. 361-478 .

Winter, S. (1968), “Toward a neo-Schumpeterian theory of the firm”, Rand Corporation, poligrafado.

Winter, S.G. (1993), "On Coase, competence and the corporation”, in O.E. Williamson e S.G. Winter (Coord.) (1993), The Nature of the Firm - Origins, Evolution, and Development, Oxford University Press, pp. 179-95.

Williamson, O.E. (1985), The Economic Institutions of Capitalism, The Free Press. 